\title{
Strain hardening and anisotropy in tensile fracture properties of sheared model Mozzarella cheeses
}

\author{
Prateek Sharma, ${ }^{*}{ }^{1}$ Peter A. Munro, ${ }^{*}$ Tzvetelin T. Dessev, ${ }^{*}$ Peter G. Wiles, $\ddagger$ and E. Allen Foegeding $\S$ \\ ${ }^{*}$ Riddet Institute, Massey University, Private Bag 11222, Palmerston North, New Zealand \\ †Dairy Technology Division, National Dairy Research Institute, Karnal-132001, Haryana, India \\ fFonterra Research and Development Centre, Private Bag 11029, Palmerston North 4442, New Zealand \\ §Department of Food, Bioprocessing and Nutrition Sciences, North Carolina State University, Box 7624, Raleigh 27695-7624
}

\begin{abstract}
We studied the tensile fracture properties of model Mozzarella cheeses with varying amounts of shear work input $(3.3-73.7 \mathrm{~kJ} / \mathrm{kg})$. After manufacture, cheeses were elongated by manual rolling at $65^{\circ} \mathrm{C}$ followed by tensile testing at $21^{\circ} \mathrm{C}$ on dumbbell-shaped samples cut both parallel and perpendicular to the rolling direction. Strain hardening parameters were estimated from stress-strain curves using 3 different methods. Fracture stress and strain for longitudinal samples did not vary significantly with shear work input up to 26.3 $\mathrm{kJ} / \mathrm{kg}$ and then decreased dramatically at $58.2 \mathrm{~kJ} / \mathrm{kg}$. Longitudinal samples with shear work input $<30 \mathrm{~kJ} /$ $\mathrm{kg}$ demonstrated significant strain hardening by all 3 estimation methods. At shear work inputs $<30 \mathrm{~kJ} / \mathrm{kg}$, strong anisotropy was observed in both fracture stress and strain. After a shear work input of $58.2 \mathrm{~kJ} / \mathrm{kg}$, anisotropy and strain hardening were absent. Perpendicular samples did not show strain hardening at any level of shear work input. Although the distortion of the fat drops in the cheese structure associated with the elongation could account for some of the anisotropy observed, the presence of anisotropy in the elongated nonfat samples reflected that shear work and rolling also aligned the protein structure.
\end{abstract}

Key words: tensile testing, strain hardening, anisotropy, Mozzarella cheese

\section{INTRODUCTION}

Hot water stretching and kneading is an essential step in the traditional manufacture of Mozzarella cheese. This process step causes the proteins to flow, giving a plastic appearance and forming a fibrous protein network aligned in the direction of stretching (McMahon

Received May 7, 2017.

Accepted September 9, 2017.

${ }^{1}$ Corresponding author: P.Sharma@massey.ac.nz, prateek.sharma@ icar.gov.in, or prateeksharma2000@yahoo.com et al., 1999). The fibrous structure is visible on a macroscopic level (Oberg et al., 1993; Sharma et al., 2016a). Sharma et al. (2016a,b, 2017) studied the effect of shear work input during this stretching and working step on the rheology and microstructure of model Mozzarella cheeses manufactured in a twin-screw Blentech cooker (Blentech Corp., Rohnert Park, CA) at $70^{\circ} \mathrm{C}$. Shear work inputs were extended well beyond normal manufacturing limits to exaggerate any changes in the cheese caused by working. Mechanical properties were characterized using a range of rheological methods, including steady shear viscosity, strain sweeps, frequency sweeps, temperature sweeps, and creep behavior. With increase in shear work input, cheeses showed increases in steady shear viscosity and storage modulus. Frequency sweeps at $70^{\circ} \mathrm{C}$ demonstrated a shift from viscoelastic liquid to viscoelastic solid. These changes all indicate work thickening of the cheese. Very high shear work inputs $(>70$ $\mathrm{kJ} / \mathrm{kg}$ ) led to major macroscopic structural changes to the cheese network, with disappearance of the fibrous structure, loss of stretch and melt, and serum syneresis. Microstructures of the overworked cheeses indicated disappearance of the fibrous character and the creation of a homogeneous structure with a fine dispersion of fat particles in a brittle protein network (Sharma et al., 2017). The observed phenomena were attributed mainly to an increase in the strength of protein-protein interactions with prolonged working.

Bast et al. (2015) developed a tensile testing method to quantitate anisotropy and strain hardening of commercial Mozzarella cheese. The method involved deliberate elongation of cheese at $60^{\circ} \mathrm{C}$ by manual rolling on a cooled metal surface to ensure that the structure was systematically aligned. Mozzarella cheeses showed strong anisotropy for both fracture stress and strain after elongation and also showed significant strain hardening in the longitudinal or fiber direction. The study indicated that tensile testing was a good method to explore anisotropy and strain hardening because fracture location and mode of failure were clearly visible. Other studies on strain hardening in dairy protein systems 
explored fine-stranded whey protein isolate gels (Lowe et al., 2003), weak $\beta$-lactoglobulin gels (Pouzot et al., 2006), and gels formed by acidifying transglutaminase cross-linked casein (Rohm et al., 2014).

Rheological properties, microstructure, and extent of anisotropy are all closely related to the functional characteristics of Mozzarella cheese for pizza application such as meltability, stretchability, elasticity, oilingoff, and blister formation (Kindstedt and Fox, 1993; Olivares et al., 2009).

Strain hardening behavior expresses the underlying arrangement of structural units and is therefore useful for understanding functional properties of food materials. Strain hardening is well explored in gluten networks because it is important to attain optimum baking performance of bread dough by aiding holding capacity and stability of gas bubbles in the bread (van Vliet et al., 1992; Kokelaar et al., 1996; Peighambardoust et al., 2006; Peressini et al., 2008; van Vliet, 2008). The effect of mechanical work on tensile fracture properties and strain hardening of flour dough has also been studied. Peighambardoust et al. (2006) and Peressini et al. (2008) observed a decrease in strain hardening upon prolonged working of flour doughs and attributed this to breakdown in the gluten network structure. The structural analogy of the anisotropic nature of gluten network and Mozzarella cheese indicates the possibility of adapting testing procedures from dough rheology for better understanding of strain hardening in Mozzarella type cheeses.

The objectives of this paper were to (1) measure the tensile fracture properties and anisotropy of model Mozzarella cheeses with varied shear work inputs (3.3-73.7 $\mathrm{kJ} / \mathrm{kg}$ ) to complement the other rheological tools we have used; (2) explore whether our model Mozzarella cheeses strain harden and to see the effect of shear work input on this strain hardening; and (3) apply to Mozzarella cheese a wider range of strain hardening measures as used for flour doughs.

\section{MATERIALS AND METHODS}

\section{Materials}

Frozen blocks $\left(-20^{\circ} \mathrm{C}\right)$ of renneted, acidified protein gel prepared from skim milk were obtained from the Fonterra Research and Development Centre (FRDC) pilot plant (Palmerston North, New Zealand). The protein gel was typically about $50 \%$ moisture and $46 \%$ protein. The frozen blocks were thawed for $1 \mathrm{~d}$ at $11^{\circ} \mathrm{C}$ and ground to a 6 -mm grind size. Cream was obtained from FRDC as a fresh lot on each trial day. Cheese salt and trisodium citrate (TSC) were procured from
Dominion Salt (Mount Maunganui, New Zealand) and Jungbunzlauer (Basel, Switzerland), respectively.

\section{Manufacture of Model Mozzarella Cheeses}

Model Mozzarella cheese was manufactured by mixing, cooking, and working protein gel, cream, water, and salt together using $150 \mathrm{rpm}$ at $70^{\circ} \mathrm{C}$ in a counter rotating twin-screw cooker (Blentech model CC-0045, Blentech Corp.; Sharma et al., 2016a). Three model cheeses were prepared: full-fat cheese, nonfat cheese, and full-fat cheese with $0.5 \%$ TSC as a chelating agent. The target composition of full-fat cheese was $23 \%$ fat, $21 \%$ protein, $53 \%$ moisture, and $1.4 \%$ salt. The same protein-to-salt and protein-to-moisture ratios as in fullfat cheese were used in nonfat cheese. Further details of processing methods, sampling times, sample storage conditions, and product compositions are given in Sharma et al. (2016a). Each experimental run was repeated twice on different days at an interval of at least 1 mo to ensure no variation arising from raw materials with similar composition but obtained from different lots.

All cheeses used in this study were frozen after manufacture. Shear work input was estimated by numerical integration of power-time curves (Sharma et al., 2016a). Shear work inputs ranged from 3.3 to $73.7 \mathrm{~kJ} / \mathrm{kg}$.

\section{Sample Preparation for Tensile Testing}

Cheese samples were prepared for tensile testing using the method of Bast et al. (2015) with some variations. Cheese samples $(\sim 300 \mathrm{~g})$ were melted by placing in closed containers at $65^{\circ} \mathrm{C}$ water bath for about $2 \mathrm{~h}$. Melted cheese was manually rolled on a cooled $\left(4^{\circ} \mathrm{C}\right)$ aluminum plate using a granite rolling pin $\left(4^{\circ} \mathrm{C}\right)$ to form a sheet. Aluminum guide strips were attached to the plate sides to achieve a sheet thickness of 3 to $4 \mathrm{~mm}$. The term "elongation" is used throughout the paper for this process. Elongation was performed for $120 \mathrm{~s}$ at $10 \mathrm{rolls} / \mathrm{min}$. Dumbbell-shaped samples were cut in both longitudinal $(\mathrm{n}=8)$ and perpendicular ( $\mathrm{n}$ $=9$ ) orientations. Samples were kept at $21^{\circ} \mathrm{C}$ for at least $1 \mathrm{~h}$ before tensile testing. Each rolling treatment was performed twice.

\section{Tensile Testing and Data Analysis}

Tensile testing on elongated cheese samples was performed on a TA.XT2plus Texture Analyzer (Stable Micro Systems Ltd., Godalming, UK) using tensile grips at $21^{\circ} \mathrm{C}$. Crosshead speed was $2 \mathrm{~mm} / \mathrm{s}$ and trigger force was $0.01 \mathrm{~N}$. The initial dimensions of the central section of each sample were measured using Vernier 
calipers. Dumbbell-shaped samples were placed carefully on both jaws avoiding any fracture during sample transfer.

Force-displacement data were converted into true stress $(\boldsymbol{\sigma}, \mathrm{Pa})$ versus Hencky strain $(\varepsilon$; Bast et al., 2015). The anisotropy ratio, $\mathrm{R}$, for fracture stress was calculated as $\sigma_{\mathrm{L}} / \sigma_{\mathrm{P}}$, where $\sigma_{\mathrm{L}}$ and $\sigma_{\mathrm{P}}$ are the fracture stresses in longitudinal and perpendicular directions, and similarly for fracture strain.

\section{Strain Hardening Parameters}

Strain hardening properties were calculated only for longitudinal samples because perpendicular samples showed no strain hardening. An empirical equation suggested by Hollomon (Kokelaar et al., 1996; van Vliet, 2008) provided 2 strain hardening parameters in uniaxial extension:

$$
\sigma=\mathrm{K}_{S H} \varepsilon_{H}^{\eta_{S H}},
$$

where $\mathrm{K}_{S H}$ is the strength coefficient $(\mathrm{Pa}), \varepsilon_{H}$ is Hencky strain, and $\eta_{S H}$ is the strain hardening index (SHI), where values of $\eta_{S H}>1$ indicate strain hardening behavior. Equation [1] was fitted $\left(\mathrm{R}^{2} \sim 0.98-0.99\right)$ to stress-strain data over the strain range from 0.4 to "0.05 before fracture."

Strain hardening is observed directly as an increase in the slope of the true stress-Hencky strain curve with increasing strain. A strain hardening ratio (SHR) was therefore calculated (Bast et al., 2015):

$$
\mathrm{SHR}=\frac{\text { Maximum modulus near fracture }}{\text { Initial modulus }} .
$$

Initial modulus was obtained by linear regression of each stress-strain curve in the strain range 0.01 to 0.25 .

Strain hardening provides stability against uneven distribution of stress and incipient localized thinning, allowing much larger extensions to occur and allowing the material to resist further thinning by locally increasing the resistance to further deformation (Dobraszczyk and Vincent, 1999). According to the Considère criterion for necking stability in uniaxial extension

$$
\frac{\mathrm{d} \sigma}{\mathrm{d} \varepsilon}=\sigma
$$

and

$$
\text { apparent strain hardening }(\mathbf{A S H})=\frac{\mathrm{d} \ln \sigma}{\mathrm{d} \varepsilon},
$$

where ASH values $>1$ indicate strain hardening (van Vliet et al., 1992; Peighambardoust et al., 2006; van Vliet, 2008).

\section{Microscopy}

Confocal laser scanning microscopy (CLSM) was done with a Zeiss LSM 510 META confocal microscope (Carl Zeiss AG, Oberkochen, Germany) according to the method of Sharma et al. (2017). Cheese slabs $(\sim 12$ $\times 4 \mathrm{~mm})$ were frozen at $-20^{\circ} \mathrm{C}$ and sectioned into 50 $\mu \mathrm{m}$ slices on a cryo-microtome. Slices were immediately transferred to glass slides, stained with $0.4 \%$ Nile red and $0.2 \%$ fast green, and covered with a coverslip. Samples were kept at $4^{\circ} \mathrm{C}$ for at least $48 \mathrm{~h}$ before imaging to allow uniform uptake of dyes.

Because nonfat cheese was translucent, its microstructure could be studied using transmission light microscopy on an Olympus BX60 (Olympus Optical Co. Ltd., Tokyo, Japan $)$. A 1-mm-thick slice $(12 \times 12$ $\mathrm{mm}$ ) of nonfat cheese was prepared using a sharp razor blade. Images were captured by a charge-coupled device camera (Axio Cam HRc, Carl Zeiss, Hallbergmoos, Germany).

\section{Rheological Measurements}

Rheological measurements were conducted on an Anton Paar MCR 301 rheometer (Anton Paar, Graz, Austria) with a 20-mm-diameter serrated plate geometry (PP20/P2) and a Peltier temperature hood (HPTD 200) using the method of Sharma et al. (2015) for steady shear rheology and that of Sharma et al. (2016b) for frequency sweeps. Disc-shaped samples 20 $\mathrm{mm}$ in diameter and $\sim 2$ to $3 \mathrm{~mm}$ thick were cut using a cork borer and wire cutter. Cheese discs were held at $70^{\circ} \mathrm{C}$ for $2 \mathrm{~min}$ to ensure isothermal conditions. The perimeter of each cheese disc was covered with a ring of soybean oil to prevent moisture loss. Flow curves were obtained at $70^{\circ} \mathrm{C}$ using the method developed by Sharma et al. (2015) and a power law model fitted to the data to obtain consistency coefficient, $\mathrm{K}$, and flow behavior index, n. Shear rates were applied with measurement times as follows: $60 \mathrm{~s}$ at $0.01 \mathrm{~s}^{-1}, 6.25 \mathrm{~s}$ at 0.1 $\mathrm{s}^{-1}, 0.5 \mathrm{~s}$ at $1 \mathrm{~s}^{-1}, 0.05 \mathrm{~s}$ at $10 \mathrm{~s}^{-1}, 0.05 \mathrm{~s}$ at $100 \mathrm{~s}^{-1}$, $0.05 \mathrm{~s}$ at $200 \mathrm{~s}^{-1}$. Frequency sweeps applied frequencies in descending order at $20^{\circ} \mathrm{C}$. Rheological measurements were conducted in triplicate.

\section{Statistical Analysis}

Descriptive statistics, nonlinear regression, and ANOVA analysis were conducted on the data using 
SPSS software (version 20; SPSS Inc./IBM Corp., Armonk, NY). Significant differences $(P<0.05)$ in the results were analyzed using single-factor ANOVA and the Duncan post hoc test to compare means.

\section{RESULTS}

\section{Tensile Fracture Properties of Sheared Model Mozzarella Cheese}

Both longitudinal and perpendicular samples exhibited nonlinear stress-strain behavior (Figure 1). At low strains $(\varepsilon<0.25)$, both longitudinal and perpendicular samples behaved in a linear manner with similar values of initial modulus. At small deformations, Hookean behavior is expected in food materials. However, at higher strain levels $(\varepsilon>0.25)$ nonlinear behavior was observed. Longitudinal samples demonstrated strain hardening with a significant increase in tensile modulus. Further measures to quantify strain hardening are explored in the section Strain Hardening of Model Mozzarella Cheeses. Perpendicular samples exhibited slight strain softening. Perpendicular samples fractured at much lower strain.

For full-fat cheese, all longitudinal samples at shear work levels $\leq 26.3 \mathrm{~kJ} / \mathrm{kg}$ produced similar stress-strain curves (Figure 2a). At small strains $(\varepsilon<0.25)$, initial modulus of longitudinal samples was about $129 \mathrm{kPa}$ at shear work levels $\leq 26.3 \mathrm{~kJ} / \mathrm{kg}$ but was much higher $(216$ $\mathrm{kPa}$ ) at $58.2 \mathrm{~kJ} / \mathrm{kg}$, indicating the creation of a stiffer structure upon working. Perpendicular samples (Figure $2 \mathrm{~b}$ ) showed much more variation in stress-strain curves with reduction in fracture strain with increasing shear work input. Longitudinal and perpendicular samples indicated strain hardening and strain weakening behavior, respectively. When a shear work of $58.2 \mathrm{~kJ} / \mathrm{kg}$ was used to make the cheese, both longitudinal and perpendicular samples showed strain weakening behavior and had a low fracture strain. When comparing longitudinal samples of the 3 model cheeses (Figure 2c), the order of initial stiffness and extent of nonlinear behavior was nonfat cheese $>$ full-fat cheese $>$ TSC-added cheese.

Longitudinal samples of full-fat cheese indicated no significant difference in fracture stress, fracture strain, or curve shape with shear work input up to $26.3 \mathrm{~kJ} /$ $\mathrm{kg}$ (Table 1), indicating similar structure and strength. However, a dramatic decrease in both fracture stress and strain occurred at $58.2 \mathrm{~kJ} / \mathrm{kg}$. The decrease $(P<$ $0.05)$ in fracture stress with increase in shear work suggested that the cheese matrix had lower strength after prolonged working. Similar observations were made from tensile testing of dough systems subjected to different levels of working (Peighambardoust et al., 2006).

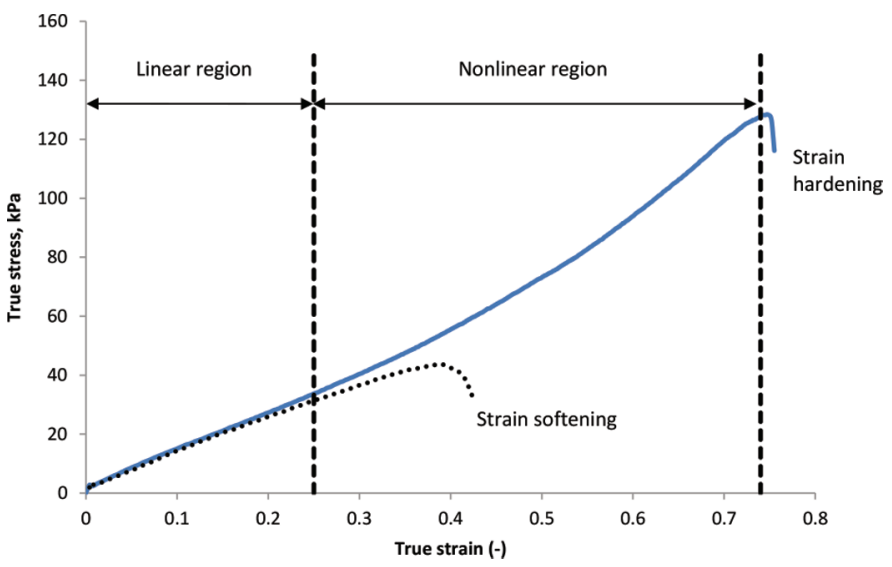

Figure 1. Typical stress-strain curves for model Mozzarella cheese samples in longitudinal (smooth line) and perpendicular (dotted line) orientations indicating strain hardening and strain softening, respectively. Longitudinal samples show linear and nonlinear regions before tensile fracture. Model Mozzarella cheeses were prepared in the Blentech cooker (Blentech Corp., Rohnert Park, CA) with $3.3 \mathrm{~kJ} / \mathrm{kg}$ of shear work at $70^{\circ} \mathrm{C}$ using a screw speed of $150 \mathrm{rpm}$. Color version available online.

The initial tensile modulus of the cheese increased dramatically from $142.1 \mathrm{kPa}$ at $26.3 \mathrm{~kJ} / \mathrm{kg}$ to $248.4 \mathrm{kPa}$ at $58.2 \mathrm{~kJ} / \mathrm{kg}$ (Table 2). Fracture stress did not change significantly with shear work input for perpendicular samples (Table 1), whereas fracture strain decreased significantly as shear work increased. Fracture strain is usually regarded as an indicator of structural arrangement, so a decrease in fracture strain with increasing shear work indicates significant differences in structure; for example, more inherent weaknesses in the structure, causing crack initiation, propagation, and fracture (Table 1, Figure 2b). The large percentage variations in fracture strain for perpendicular samples (Table 1) probably arise from the random occurrence of such structural weaknesses or imperfections. At low shear work inputs of 3.3 to $26.3 \mathrm{~kJ} / \mathrm{kg}$ for the full-fat cheeses, longitudinal samples had higher values for both fracture stress $\left(\sigma_{\mathrm{f}}=115-128 \mathrm{kPa}\right)$ and fracture strain $\left(\varepsilon_{\mathrm{f}}=\right.$ $0.74-0.77)$ than the perpendicular samples $\left(\sigma_{\mathrm{f}}=27-40\right.$ $\left.\mathrm{kPa} ; \varepsilon_{\mathrm{f}}=0.29-0.37\right)$. Anisotropy index was higher for fracture stress (3.0-4.5) than for fracture strain $(2.0-$ $2.6)$. Both indicated significant anisotropy $(P<0.05)$ in fracture properties. At a shear work input of $58.2 \mathrm{~kJ} /$ $\mathrm{kg}$, anisotropy had disappeared for both fracture stress and fracture strain (Table 1).

Fracture stress for nonfat cheese was $\sim 33 \%$ higher $(P$ $<0.05)$ for longitudinal samples and $\sim 59 \%$ higher $(P$ $<0.05)$ for perpendicular samples than that for full-fat cheese with similar shear work input (Table 1). Nonfat cheese had a much higher protein content than full-fat cheese, so more structural protein elements were pres- 
ent per unit of cross-sectional area in the nonfat cheese, giving rise to higher values of fracture stress. Adding TSC to full-fat cheese resulted in $\sim 32 \%$ lower $(P<$

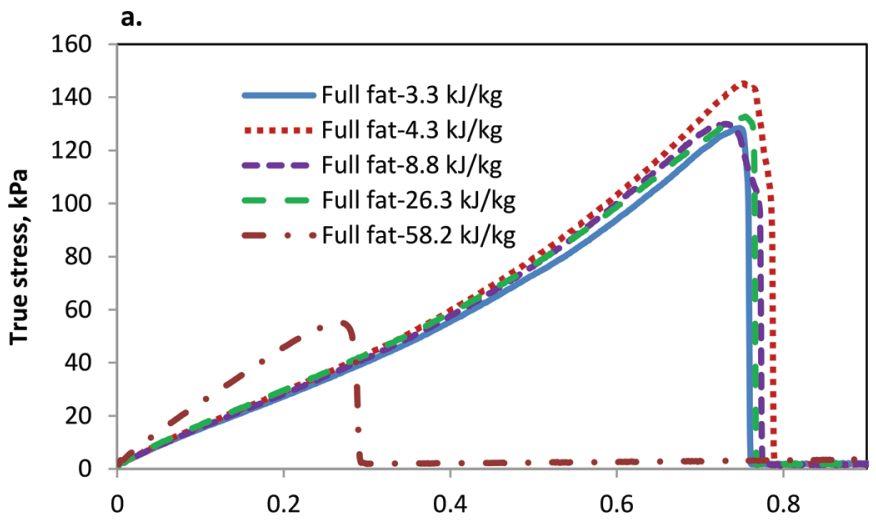

b.

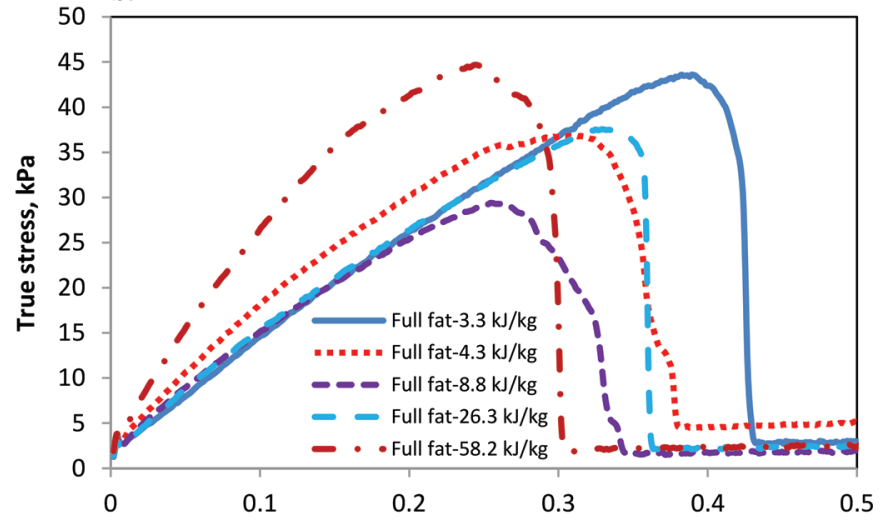

c.

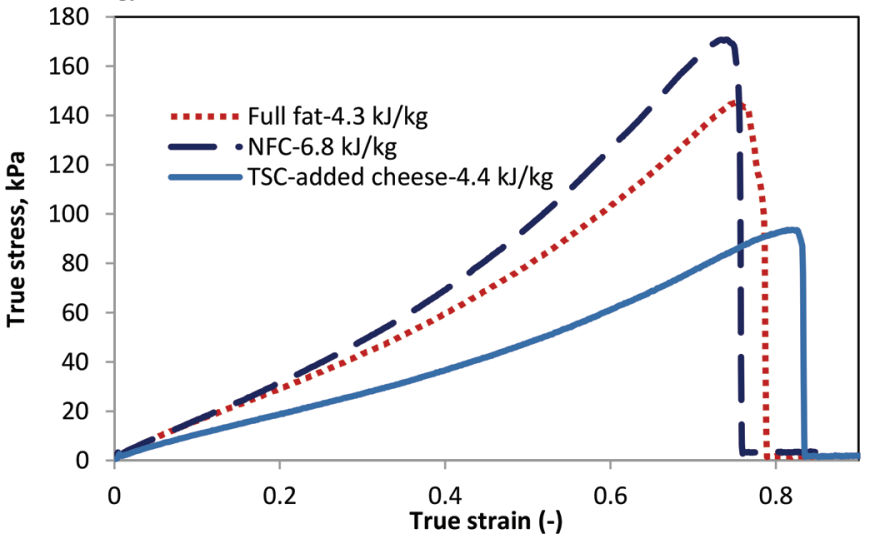

Figure 2. Stress-strain curves for model Mozzarella cheeses. Fullfat cheeses with varied amounts of shear work (3.3 to $58.2 \mathrm{~kJ} / \mathrm{kg}$ ) were cut in (a) longitudinal and (b) perpendicular orientations; and (c) full-fat, nonfat (NFC), and trisodium citrate (TSC)-added cheeses were compared at similar shear work levels in the longitudinal orientation. Model Mozzarella cheeses were prepared in the Blentech cooker (Blentech Corp., Rohnert Park, CA) at $70^{\circ} \mathrm{C}$ using screw speed of 150 rpm. Typical curves close to the mean behavior were chosen from $\mathrm{n}$ $=16$ longitudinal samples and $\mathrm{n}=18$ perpendicular samples. Color version available online. 


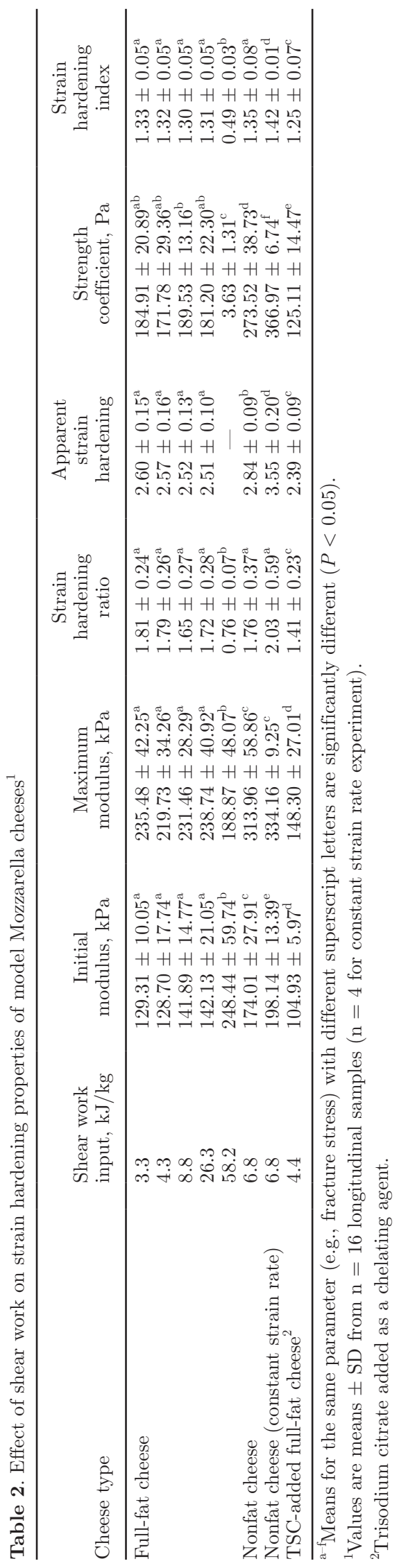

0.05) fracture stress than full-fat cheese without TSC for both longitudinal and perpendicular samples. This may be attributed to chelation of calcium by the added TSC, resulting in loose binding of the cheese matrix (Sharma et al., 2016a).

The different cheeses behaved very differently during the elongation process (Figure 3) and this affected their tensile fracture behavior. At low and moderate shear work inputs, the cheese elongated well, giving a smooth, homogeneous cheese layer (Figure 3a). At $58.2 \mathrm{~kJ} / \mathrm{kg}$ shear work, the cheese did not flow well, resulting in a heterogeneous cheese layer with several weak spots (Figure $3 \mathrm{~b}$ ). With excessive working (73.7 $\mathrm{kJ} / \mathrm{kg}$ ), rolling could not be conducted satisfactorily as the cheese was brittle, even at $65^{\circ} \mathrm{C}$, there was no continuous flowing mass, and the resulting cheese sheet was highly heterogeneous (Figure 3c). Representative dumbbell tensile samples could not be cut from the cheese sheet.

\section{Strain Hardening of Model Mozzarella Cheeses}

Strain hardening parameters for samples cut in longitudinal orientation are presented in Table 2 . The least variable parameter was SHI $(\mathrm{CV} \sim 4 \%)$ followed by ASH $(\sim 7 \%)$, and then SHR $(\sim 13 \%)$. The SHR method was the most variable and is the ratio of 2 moduli. In contrast, $\mathrm{ASH}, \mathrm{K}_{S H}$, and $\mathrm{SHI}$ were estimated from fits to the whole nonlinear portion of the fracture curve and were probably a better indicator of strain hardening. For the full-fat cheeses with shear work input up to $26.3 \mathrm{~kJ} / \mathrm{kg}$, SHR varied from 1.65 to 1.81 , ASH from 2.51 to 2.60 , and SHI from 1.30 to 1.33. For all 3 parameters, values $>1$ indicate strain hardening (Bast et al., 2015 for SHR; Peighambardoust et al., 2006 for ASH; van Vliet et al., 1992 and van Vliet, 2008 for SHI), so strain hardening was significant. In contrast, at a shear work input of $58.2 \mathrm{~kJ} / \mathrm{kg}$, strain softening was observed, with both SHR (0.76) and SHI (0.49) being $<1$. Decreased $(P<0.05)$ strain hardening with an increase in shear work input from 26.3 to $58.2 \mathrm{~kJ} / \mathrm{kg}$ suggested weakening of the cheese matrix or a higher prevalence of fracture initiating cracks with progressive working. Peighambardoust et al. (2006) also reported a reduction in $\mathrm{ASH}$ values with progressive mixing of bread dough. Zheng et al. (2000), Gras et al. (2000), and Peressini et al. (2008) concluded that over-mixing led to diminished tensile fracture properties of bread dough under extension tests.

The nonfat cheese and TSC added cheese samples also showed significant strain hardening for all $3 \mathrm{pa}-$ rameters (Table 2). The ASH and SHI values were significantly higher $(P<0.05)$ for nonfat cheese $(2.84$ and 1.35) and lower $(P<0.05)$ for TSC-added cheese 

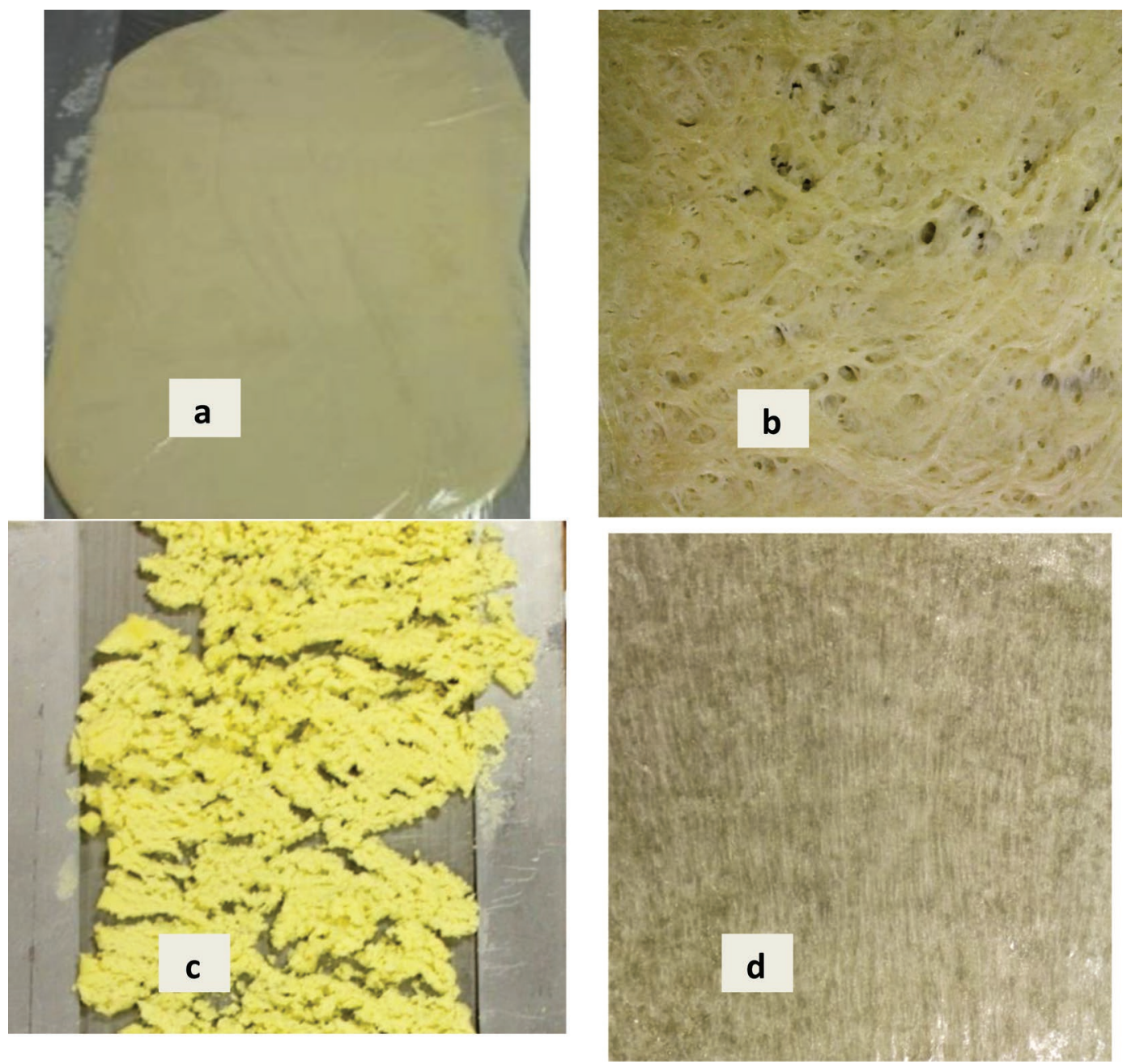

Figure 3. Visual appearance of elongated model Mozzarella cheeses. Cheese samples were prepared in the Blentech cooker (Blentech Corp., Rohnert Park, CA) with varied amounts of shear work input at $70^{\circ} \mathrm{C}$ and $150 \mathrm{rpm}$; full-fat cheese at (a) $8.8 \mathrm{~kJ} / \mathrm{kg}$, (b) $58.2 \mathrm{~kJ} / \mathrm{kg}$, and (c) 73.7 $\mathrm{kJ} / \mathrm{kg}$; and nonfat cheese at $6.8 \mathrm{~kJ} / \mathrm{kg}(\mathrm{d})$. Color version available online.

(2.39 and 1.25) than for full-fat cheese (2.57 and 1.32) with similar shear work input (Table 2). Table 2 also presents results for fracture tests performed on nonfat cheese at constant strain rate rather than constant crosshead speed. The TA.XT2plus was programmed to increase crosshead speed with time to maintain a constant strain rate of $0.2 \mathrm{~s}^{-1}$. This indicated an even higher extent of strain hardening, with ASH and SHI both being significantly higher (3.55 and 1.42; $P<$ 0.05 ) than at constant crosshead speed (2.84 and 1.35).

\section{Structural Anisotropy in Model Cheeses}

Cheeses before elongation exhibited microstructural anisotropy with orientation of fat in one direction (Figure 4, panels a1 and a2). Tensile testing of these unrolled cheeses during preliminary studies, however, showed no significant anisotropy for either fracture stress or fracture strain. After melting and elongation, the same cheeses still revealed signs of microstructural anisotropy with the fat channels enlarged (Figure 4, panels b1, b2, and b3). The structure showed globular fat in some regions (Figure 4, panel b3) and coalesced, elongated fat particles in other regions (Figure 4, panel b2). This microstructural alignment of fat particles was presumably a major contributor to anisotropy in tensile fracture properties. Nonfat cheese samples also indicated microstructural alignment of the protein structure by transmission light microscopy (Figure 4c). A simple photograph of nonfat cheese macrostructure also suggested orientation in the direction of rolling (Figure 3d). Similar structural orientation has been reported 


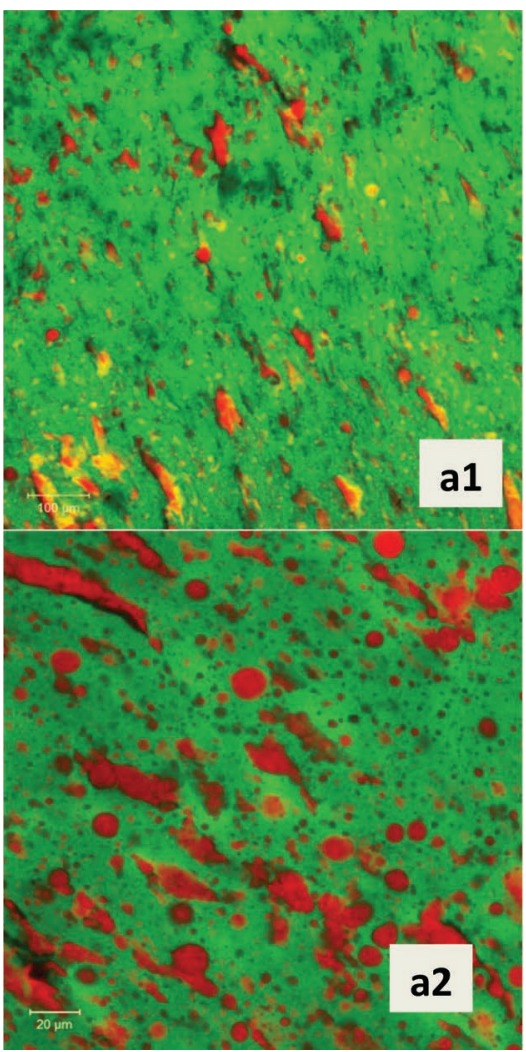

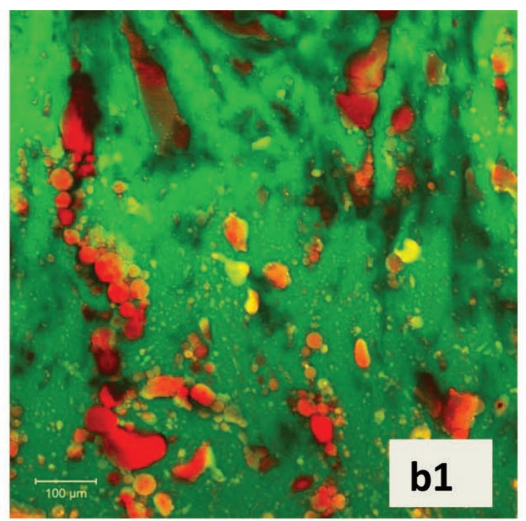

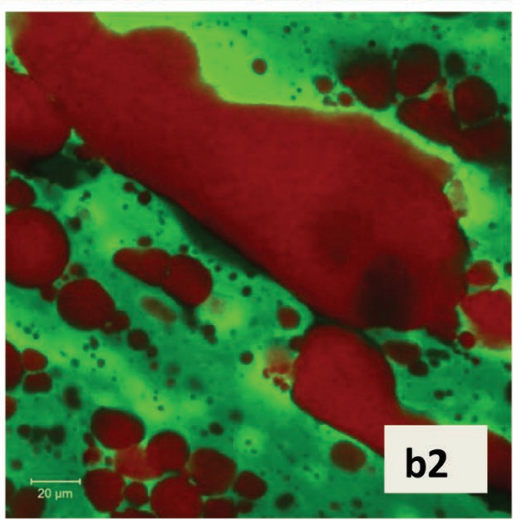

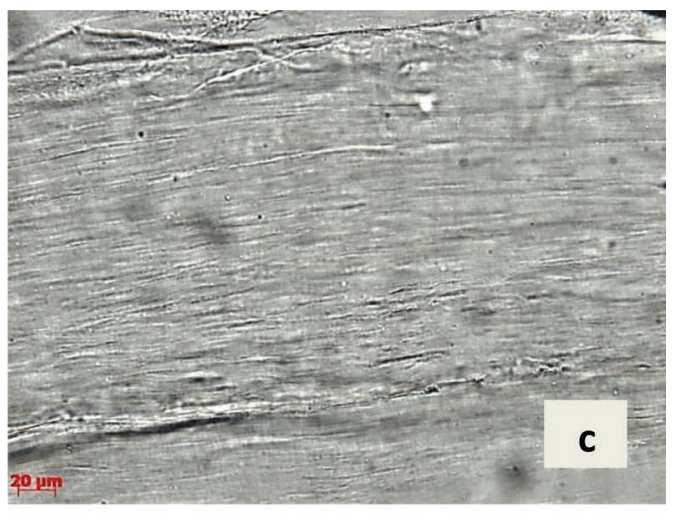

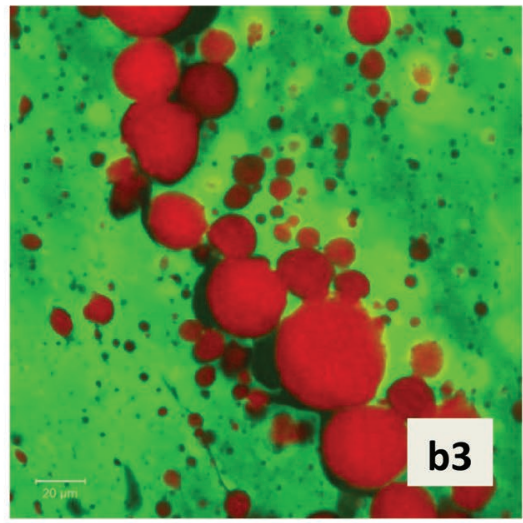

Figure 4. Microstructures of model Mozzarella cheeses: confocal laser scanning microscopy images of normal (a1, a2) and elongated (b1, b2, b3) full-fat Mozzarella cheeses after $26.3 \mathrm{~kJ} / \mathrm{kg}$ of shear work input; and light microscopy image of nonfat Mozzarella cheese (c) after $6.8 \mathrm{~kJ} /$ $\mathrm{kg}$ of shear work input. Cheese samples were prepared in the Blentech cooker (Blentech Corp., Rohnert Park, CA) at $70^{\circ} \mathrm{C}$ and $150 \mathrm{rpm}$. Red $($ darker gray $)=$ fat, green $($ lighter gray $)=$ protein, and black $=$ air/water. Color version available online.

previously at various length scales for nonfat cheeses (Mizuno and Lucey, 2005), supporting our observations.

\section{Small Strain Oscillatory Shear Rheology of Model Cheeses}

Mechanical spectra at $20^{\circ} \mathrm{C}$ of full-fat, nonfat, and TSC-added cheeses are shown in Figure 5. All 3 cheeses exhibited viscoelastic solid behavior [storage modulus $\left(\mathrm{G}^{\prime}\right)>$ loss modulus $\left(\mathrm{G}^{\prime \prime}\right)$ across all frequencies tested] with low and similar frequency dependence (slope, $n_{\mathrm{f}}$ $\sim 0.16-0.18$ ), suggesting the presence of a physically stable network. The $\mathrm{n}_{\mathrm{f}}$ values are consistent with those reported for casein gels and fat-filled casein gels (Zhou and Mulvaney, 1998). Storage moduli for full-fat cheese were higher than those for nonfat cheese and TSCadded cheese, probably because of the contribution from solid fat at $20^{\circ} \mathrm{C}$ (Zhou and Mulvaney, 1998). The storage modulus of milkfat $\left(\mathrm{G}_{\mathrm{f}}^{\prime}=292 \mathrm{kPa}\right)$ was higher than that of the cheese matrix $\left(\mathrm{G}_{\mathrm{m}}{ }^{\prime}=164 \mathrm{kPa}\right)$ at $20^{\circ} \mathrm{C}$ (Yang et al., 2011), so fat would be expected to reinforce the matrix.

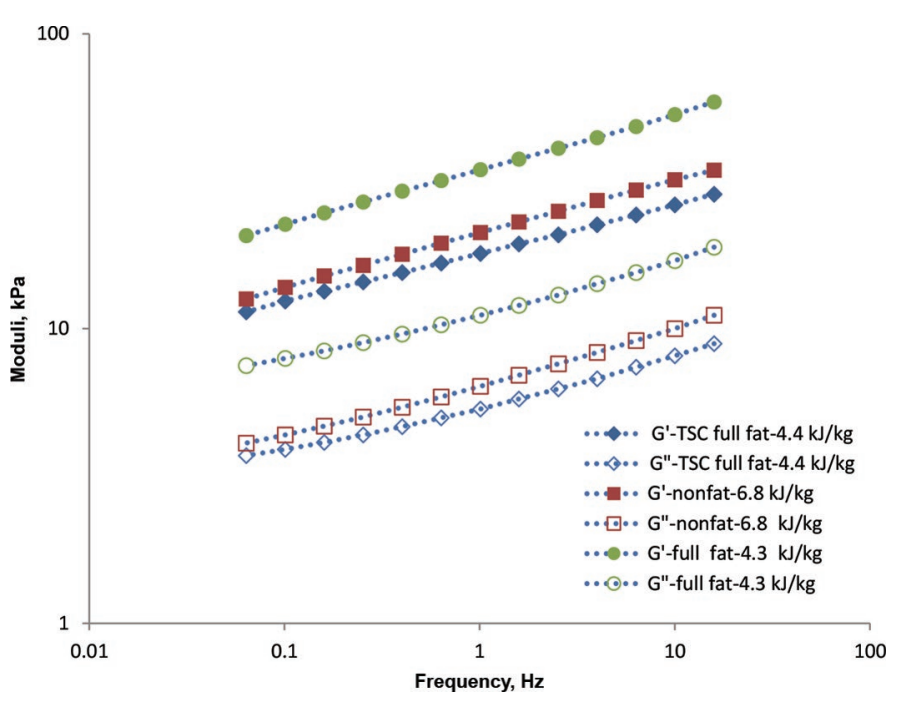

Figure 5. Storage moduli ( $\mathrm{G}^{\prime}$; closed symbols) and loss moduli $\left(\mathrm{G}^{\prime \prime}\right.$; open symbols) of model Mozzarella cheeses obtained from frequency sweeps at $20^{\circ} \mathrm{C}$ on full-fat, nonfat, and trisodium citrate (TSC)-added cheeses by giving $4.3,6.8$, and $4.4 \mathrm{~kJ} / \mathrm{kg}$ of shear work input, respectively, at $70^{\circ} \mathrm{C}$ and $150 \mathrm{rpm}$. Color version available online. 
Table 3. Effect of rolling on steady shear rheology of model Mozzarella cheese ${ }^{1}$ at $70^{\circ} \mathrm{C}$

\begin{tabular}{lcr}
\hline Item & Normal cheese & Rolled cheese \\
\hline Consistency coefficient, $\mathrm{Pa} \cdot \mathrm{s}^{\mathrm{n}}$ & $131.2 \pm 10.2^{\mathrm{a}}$ & $188.2 \pm 20.2^{\mathrm{b}}$ \\
Flow behavior index, $\mathrm{n}$ & $0.73 \pm 0.01^{\mathrm{a}}$ & $0.72 \pm 0.01^{\mathrm{b}}$ \\
Apparent viscosity at $0.01 \mathrm{~s}^{-1}, \mathrm{~Pa} \cdot \mathrm{s}$ & $449.3 \pm 8.3^{\mathrm{a}}$ & $682.7 \pm 76.3^{\mathrm{b}}$ \\
\hline${ }^{\mathrm{a}, \mathrm{b}}$ Means within a row with different superscript letters are significantly different $(P<0.05)$. \\
${ }^{1}$ Cheese was prepared by giving $26.3 \mathrm{~kJ} / \mathrm{kg}$ of shear work input at $150 \mathrm{rpm}$ and $70^{\circ} \mathrm{C}$. Values are means $\pm \mathrm{SD}$ \\
from 4 repetitions.
\end{tabular}

\section{Steady Shear Rheology of Elongated Model Cheeses}

Bast et al. (2015) noted that the manual rolling process caused considerable work thickening in as little as $18 \mathrm{~s}$, whereas shear in the Blentech caused almost no work thickening after 4,000 s at $50 \mathrm{rpm}$ (Sharma et al., 2016a). It is interesting to know whether the work thickening from elongation was only evident in tensile fracture properties or whether it also caused changes in steady shear viscosity. Consistency coefficient and apparent viscosity at $0.01 \mathrm{~s}^{-1}$ increased by 1.43 and 1.52 times, respectively $(P<0.05)$, after elongation (Table 3 ), indicating significant work thickening upon elongation. Elongation also increased tensile fracture stress by 5.7 times parallel to the fibers and by 2.1 times perpendicular to the fibers (Bast et al., 2015). The type of deformation is quite different in measurement of the 2 properties, however. Tensile fracture measures the strength of a material while pulling in one direction, whereas steady shear rheology measures resistance to shear flow.

\section{DISCUSSION}

The anisotropy index range for fracture stress of 3.01 to 4.49 (Table 1) for our elongated model cheeses was similar to the value for an elongated commercial Mozzarella cheese (3.0) but less than that for string cheese (6.0; Bast et al., 2015) or fibrous fat-calcium caseinate materials (highest at 14.2; Manski et al., 2008). Possible reasons for the higher degree of anisotropy in other reports were the higher protein-to-moisture ratio for string cheese (0.59 vs. 0.39), the presence of transglutaminase cross-linking enzyme in the material of Manski et al. (2008), and the use of specific shearing processes that increased the fibrous character in both examples quoted.

To help explain anisotropy in full-fat, elongated model Mozzarella cheese, we propose a structural model (Figure 6a). The proposed model is based upon the assumption that the fracture process uses a viscolastic mode of energy release in isothermal conditions. A continuous protein gel contains a dispersed phase of fat particles elongated in the direction of rolling, as observed by
CLSM (Figure 4b). At small strains $(<0.25)$, the stress-strain curves for longitudinal and perpendicular samples are very similar because the main deformation is in the gel network; for example, initial modulus $126 \mathrm{kPa}$ for longitudinal and $116 \mathrm{kPa}$ for perpendicular samples (Figure 1). As strain increased perpendicular to the long axis of the fat particles, fracture was initiated at low strains because of the large amount of structurally weak fat and fat-protein interface in this orientation. This resulted in lower values of fracture stress and strain for the perpendicular orientation (Table 1). As strain increased parallel to the long axis of the fat particles, fracture occurred in the gel phase, because there was much less fat-protein interface. Fracture was reached at higher strains and therefore higher fracture stress. The anisotropy of cooked meat has been explained in a similar way, with the muscle fibers having higher strength than the connective tissue between the fibers (Purslow, 1985).

Nonfat cheese was also highly anisotropic (Table 1) and showed evidence of structural alignment at a macroscopic (visual) scale (Figure 3d) and a microscopic scale (Figure 4c). Structural alignment on a microscopic scale was also observed by Mizuno and Lucey (2005). Nonfat Mozzarella cheese has been shown to contain serum pockets (Paulson et al., 1998; Pastorino et al., 2002; McMahon et al., 2005). These pockets would be aligned in the direction of rolling, forming weak interfaces between the protein fibers as depicted in Figure 6a. An alternative explanation is that shearing in the Blentech or elongation by rolling may cause localized fracture or shear banding, as observed in dough systems (Kieffer and Stein, 1999; Peighambardoust et al., 2006), resulting in reduced bond strength between fractured planes. Shear banded gluten structures led to a fibrous texture and were regarded as a major cause for structural anisotropy in sheared dough (Peighambardoust et al., 2006). Strain exerted in the perpendicular orientation may cause early fracture because of weak bonding between fibers (Taneya et al., 1992; Ak and Gunasekaran, 1997), whereas strain in the longitudinal orientation requires fracture of the fibers, resulting in higher fracture strains and stresses. This explanation for nonfat cheese anisotropy must be combined with 
that above to obtain a more complete picture for fullfat cheese; that is, alignment of the protein structure is an important factor in explaining the anisotropy of full-fat cheese. The observed changes and distortions of the fat phase were probably an indicator of related microstructural changes occurring in the protein phase.

Strain hardening in flour dough has been more widely studied (e.g., van Vliet et al., 1992; Kokelaar et al., 1996; Peighambardoust et al., 2006; Peressini et al., 2008; van Vliet, 2008) than strain hardening of protein structures based on casein. Peighambardoust et al. (2006) reported that flour doughs strain hardened perpendicular to the fibers as well as parallel and that fracture strain was often higher for perpendicular samples than for longitudinal samples. Fracture stress usually showed no anisotropy apart from dough from one type of flour (Spring). The results of Manski et al. (2008) using sheared and transglutaminase cross-linked casein structures are more similar to ours in that strong anisotropy was observed and only longitudinal samples strain hardened, not perpendicular samples. A possible model to explain strain hardening suggests 2 casein structural elements - individual polymer molecules and elongated clusters of cross-linked casein polymers (Figure 6b). Cross-linked elements are assumed to be stiffer. After strain hardening, 3 major changes are depicted: both elements are more aligned, the initial cross-links are more tightly bound, and additional cross-linking has occurred. Zhang et al. (2007) proposed calcium-induced junction zones as a possible reason for strain hardening behavior in alginate gels. The crosslinks depicted in Figure $6 \mathrm{~b}$ would have a similar role to these junction zones in causing strain hardening, and calcium is again likely to be involved.

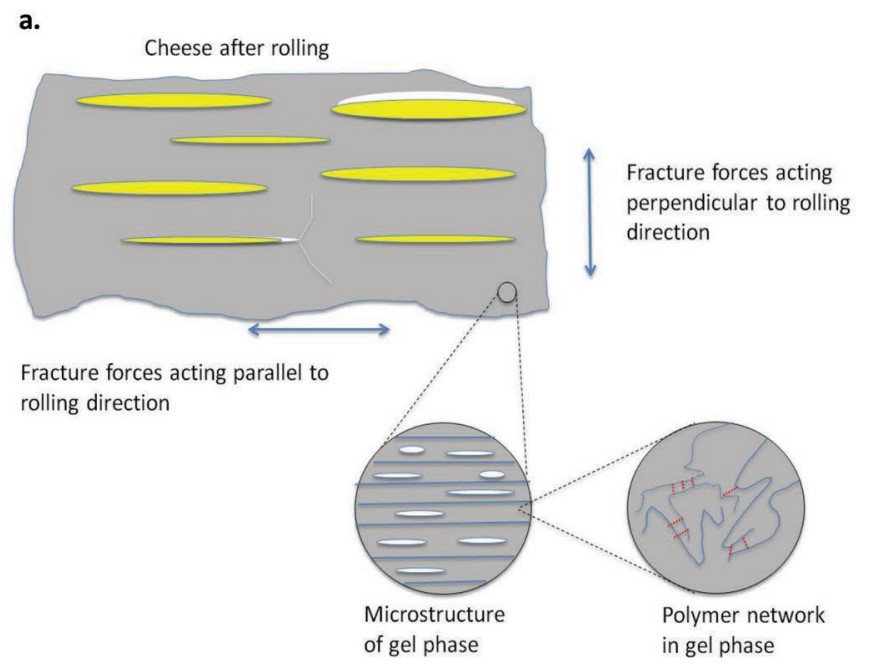

The loss of both strain hardening and anisotropy of full-fat cheese at high shear work input $(58 \mathrm{~kJ} / \mathrm{kg})$ derived from changes in the microscopic structure of the material. The presence of fat and serum channels in Mozzarella-type cheeses is widely reported (Paulson et al., 1998; McMahon et al., 1999, 2005; Mizuno and Lucey, 2005). Sharma et al. (2017) presented CLSM images of striated protein structures with aligned fatserum channels at moderate shear work levels (3.3-25.3 $\mathrm{kJ} / \mathrm{kg}$ ) in model Mozzarella cheeses and attributed this to the laminar mixing action in the Blentech. These striated structures lead to mechanical and structural anisotropy in fat-protein networks at various length scales (Cervantes et al., 1983; Ak and Gunasekaran, 1997; Manski et al., 2008; Bast et al., 2015; Sharma et al., 2015). At high shear work inputs $(>58 \mathrm{~kJ} / \mathrm{kg})$, the striated structure had disappeared and a macroscopically homogeneous, isotropic cheese structure occurred, with finely dispersed fat and no fibrous nature or stretch (Sharma et al., 2016a, 2017). This cheese showed no structural or mechanical anisotropy. Parallel behavior was reported for prolonged working of flour dough in a Z-blade mixer (Peighambardoust et al., 2006). Decreases in tensile fracture stress, fracture strain, and ASH were observed with progressive mixing, indicating weakening of the dough matrix. Strain hardening in flour dough depends on the amount and quality of gluten so the loss of ASH was attributed to extensive breakdown of the gluten network structures.

The higher values of fracture stress for nonfat cheese compared with full-fat cheese are because the fat particles act as weak areas in the structure. Bast et al. (2015) demonstrated that the tensile strength of milkfat at $21^{\circ} \mathrm{C}$ was very low. It is interesting that the strain

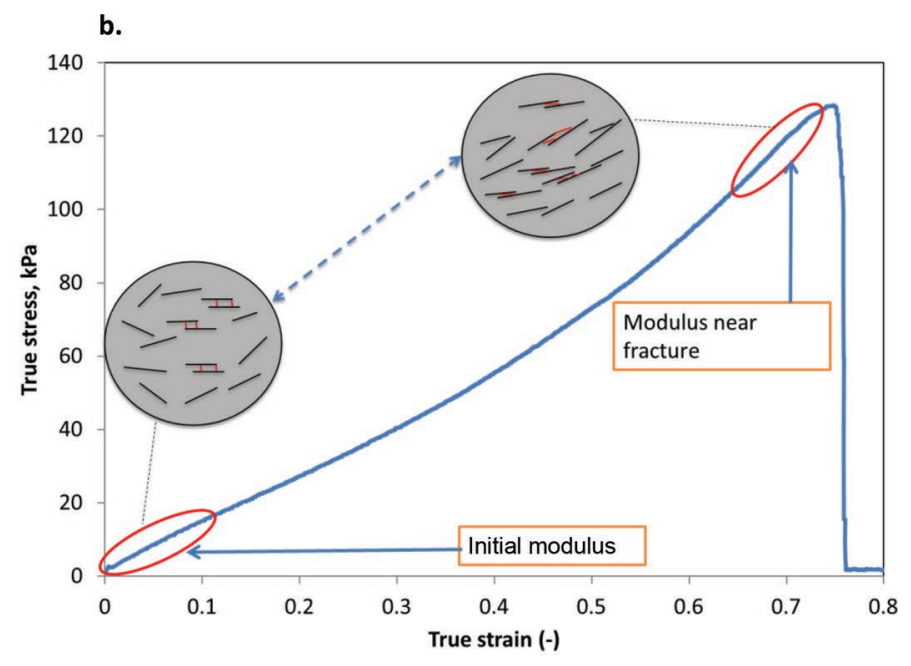

Figure 6. Schematic model explaining structural basis for anisotropy (a) and strain hardening (b) during tensile fracture of model Mozzarella cheeses. Gray and yellow areas (white areas in print version) indicate gel phase and fat phase, respectively. White pockets in gel phase indicate serum/water portion. Further structural elements within the gel phase are presented in magnified gray circles. Color version available online. 
hardening parameters for nonfat cheese were mostly not significantly different from those for full-fat cheese in spite of the higher protein content and the absence of low-strength fat in the structure. The addition of a calcium-chelating salt (TSC) to the cheese was expected to result in reduced but still flexible interactions between proteins in the structure, leading to a weaker but still cohesive structure (Sharma et al., 2016a). Fracture stress for TSC-added cheese $(78.5 \mathrm{kPa})$ was much lower $(P<0.05)$ than that for full-fat cheese $(115.7$ $\mathrm{kPa})$ or nonfat cheese $(159.2 \mathrm{kPa}$; Table 1$)$ as expected, but fracture strain was not significantly different. It is interesting that the addition of TSC reduced work thickening in the Blentech to a very low level (Sharma et al., 2016a) but did not reduce strain hardening very much (Table 2). Cheese with TSC still strain hardens, as observed by all 3 measures used. The role of calcium in the strain hardening bonding mechanism appears to be less important than the work thickening bonding mechanism. It would be interesting to look at the effect of extent of chelation of calcium in detail on rheological and fracture properties of cheese.

Steady shear viscosity increased by $52 \%$ after simple elongation of model Mozzarella cheese for $120 \mathrm{~s}$, whereas shearing in the Blentech at $50 \mathrm{rpm}$ for 4,000 s caused only small increases in steady shear viscosity (Sharma et al., 2016a). The one-dimensional elongational flow caused by rolling with simultaneous cooling into the more elastic region was apparently very effective at work thickening. One possible explanation of the results is that rolling causes elongation of the primary protein particles, thus increasing viscosity because the particles with a higher aspect ratio occupy more hydrodynamic volume. On the other hand, remelting of elongated cheese leads to relaxation of structure and decrease in anisotropy with some loss of strength (Bast et al., 2015).

One aspect of our results that is not well understood is that, although the structure is macroscopically fibrous and the microstructure shows anisotropy, there is no anisotropy in the stress-strain curves at strains below about 0.25 (Figure 1). The anisotropy only develops at higher strains and is largely related to the fact that longitudinal samples strain harden at strains $>0.25$, whereas perpendicular samples begin to strain weaken and then fracture. Based on the previous discussion by Bast et al. (2015), we suggest one possible mechanism. In the initial or linear region of the stress-strain curve, strain is merely straightening curves or bends in the protein network, which may be the same in both orientations. In the exponential or strain hardening region, where straightening has reached its limit, the fibers in the longitudinal direction need to be stretched or move past one another, leading to strain hardening. In the perpendicular orientation, the fibers are pulled further apart, the interfaces are weak, and there might be more microcracks for initiation of fracture. This plausible mechanism will require further experimental evidence for validation.

\section{CONCLUSIONS}

Both strain hardening and anisotropy were observed after elongation in sheared model Mozzarella cheeses at moderate levels of shear work $(3.3-26.3 \mathrm{~kJ} / \mathrm{kg})$. Structural alignments of both protein and fat phases were regarded as major factors contributing to this behavior. Strain hardening and anisotropic character were absent from a model cheese with prolonged working $(>58 \mathrm{~kJ} /$ $\mathrm{kg}$ ) because the structure was homogeneous and isotropic but contained several weak spots. Anisotropy and strain hardening were also observed with nonfat cheese. We attribute this to the presence of macroscopic protein fibers in the direction of rolling, even in the absence of fat. Schematic models are proposed to explain strain hardening and anisotropy in a full-fat model Mozzarella cheese. The model consists of fat dispersed in a gel matrix having 2 structural elements, cross-linked and non-cross-linked caseins.

\section{ACKNOWLEDGMENTS}

The authors are grateful to Fonterra Co-operative Group and the Ministry for Primary Industries for funding this project via the Transforming the Dairy Value Chain Primary Growth Partnership programme in Food Structure Design. We thank Robbie Buwalda, Bhavin Parmar, Ben Somerton, Grant Bleakin, Dave Griffin, and Ken Anderson for their help with the Blentech trials at Fonterra Research and Development Centre (FRDC; Palmerston, North, New Zealand). We thank Elizabeth Nickless and Michael Loh, FRDC, for helping with confocal laser scanning microscopy and light microscopy analysis of cheese samples.

\section{REFERENCES}

Ak, M. M., and S. Gunasekaran. 1997. Anisotropy in tensile properties of mozzarella cheese. J. Food Sci. 62:1031-1033. https://doi.org/ 10.1111/j.1365-2621.1997.tb15031.x.

Bast, R., P. Sharma, H. K. B. Easton, T. T. Dessev, M. Lad, and P. A. Munro. 2015. Tensile testing to quantitate the anisotropy and strain hardening of Mozzarella cheese. Int. Dairy J. 44:6-14. https://doi.org/10.1016/j.idairyj.2014.12.006.

Cervantes, M. A., D. B. Lund, and N. F. Olson. 1983. Effects of salt concentration and freezing on Mozzarella cheese texture. J. Dairy Sci. 66:204-213. https://doi.org/10.3168/jds.s0022-0302(83)81778 -0 .

Dobraszczyk, B. J., and J. F. V. Vincent. 1999. Measurement of mechanical properties of food materials in relation to texture: The material approach. Pages 99-151 in Food Texture: Measurement 
and Perception. A. J. Rosenthal, ed. Aspen Publishers, Frederick, MD.

Gras, P. W., H. C. Carpenter, and R. S. Anderssen. 2000. Modelling the developmental rheology of wheat-flour dough using extension tests. J. Cereal Sci. 31:1-13. https://doi.org/10.1006/jcrs.1999 .0293 .

Kieffer, R., and N. Stein. 1999. Demixing in wheat doughs - Its influence on dough and gluten rheology. Cereal Chem. 76:688-693. https://doi.org/10.1094/cchem.1999.76.5.688.

Kindstedt, P. S., and P. F. Fox. 1993. Effect of manufacturing factors, composition, and proteolysis on the functional characteristics of mozzarella cheese. Crit. Rev. Food Sci. Nutr. 33:167-187. https:// doi.org/10.1080/10408399309527618.

Kokelaar, J. J., T. van Vliet, and A. Prins. 1996. Strain hardening properties and extensibility of flour and gluten doughs in relation to breadmaking performance. J. Cereal Sci. 24:199-214. https:// doi.org/10.1006/jcrs.1996.0053.

Lowe, L. L., E. A. Foegeding, and C. R. Daubert. 2003. Rheological properties of fine-stranded whey protein isolate gels. Food Hydrocoll. 17:515-522. https://doi.org/10.1016/s0268-005x(03)00014-6.

Manski, J. M., E. E. J. van der Zalm, A. J. van der Goot, and R. M. Boom. 2008. Influence of process parameters on formation of fibrous materials from dense calcium caseinate dispersions and fat. Food Hydrocoll. 22:587-600. https://doi.org/10.1016/j.foodhyd .2007 .02 .006

McMahon, D. J., R. L. Fife, and C. J. Oberg. 1999. Water partitioning in Mozzarella cheese and its relationship to cheese meltability. J. Dairy Sci. 82:1361-1369. https://doi.org/10.3168/jds.s0022 -0302(99)75361-0.

McMahon, D. J., B. Paulson, and C. J. Oberg. 2005. Influence of calcium, $\mathrm{pH}$, and moisture on protein matrix structure and functionality in direct-acidified nonfat Mozzarella cheese. J. Dairy Sci. 88:3754-3763. https://doi.org/10.3168/jds.S0022-0302(05)73061 $-7$.

Mizuno, R., and J. A. Lucey. 2005. Effects of emulsifying salts on the turbidity and calcium-phosphate-protein interactions in casein micelles. J. Dairy Sci. 88:3070-3078. https://doi.org/10.3168/jds .S0022-0302(05)72988-x.

Oberg, C. J., W. R. McManus, and D. J. McMahon. 1993. Microstructure of Mozzarella cheese during manufacture. Food Struct. $12: 251-258$.

Olivares, M. L., S. E. Zorrilla, and A. C. Rubiolo. 2009. Rheological properties of mozzarella cheese determined by creep/recovery tests: Effect of sampling direction, test temperature and ripening time. J. Texture Stud. 40:300-318. https://doi.org/10.1111/j.1745 $-4603.2009 .00183 . x$

Pastorino, A. J., R. I. Dave, C. J. Oberg, and D. J. McMahon. 2002 Temperature effect on structure-opacity relationships of nonfat Mozzarella cheese. J. Dairy Sci. 85:2106-2113. https://doi.org/10 .3168/jds.S0022-0302(02)74288-4.

Paulson, B. M., D. J. McMahon, and C. J. Oberg. 1998. Influence of sodium chloride on appearance, functionality, and protein arrangements in nonfat Mozzarella cheese. J. Dairy Sci. 81:2053-2064. https://doi.org/10.3168/jds.s0022-0302(98)75780-7.

Peighambardoust, S. H., A. J. van der Goot, T. van Vliet, R. J. Hamer, and R. M. Boom. 2006. Microstructure formation and rheological behaviour of dough under simple shear flow. J. Cereal Sci. 43:183-197. https://doi.org/10.1016/j.jcs.2005.10.004.
Peressini, D., S. H. Peighambardoust, R. J. Hamer, A. Sensidoni, and A. J. van der Goot. 2008. Effect of shear rate on microstructure and rheological properties of sheared wheat dough. J. Cereal Sci 48:426-438. https://doi.org/10.1016/j.jcs.2007.10.008.

Pouzot, M., T. Nicolai, L. Benyahia, and D. Durand. 2006. Strain hardening and fracture of heat-set fractal globular protein gels. J. Colloid Interface Sci. 293:376-383. https://doi.org/10.1016/j.jcis .2005.06.074.

Purslow, P. P. 1985. The physical basis of meat texture: Observation on the fracture behaviour of cooked bovine M-semitendinosus. Meat Sci. 12:39-60. https://doi.org/10.1016/0309-1740(85)90024 -5 .

Rohm, H., F. Ullrich, C. Schmidt, J. Lobner, and D. Jaros. 2014 Gelation of cross-linked casein under small and large shear strain. J. Texture Stud. 45:130-137. https://doi.org/10.1111/jtxs.12056.

Sharma, P., T. T. Dessev, P. A. Munro, P. G. Wiles, G. Gillies, M. Golding, B. James, and P. Janssen. 2015. Measurement techniques for steady shear viscosity of Mozzarella-type cheeses at high shear rates and high temperature. Int. Dairy J. 47:102-108. https://doi .org $/ 10.1016 /$ j.idairyj.2015.03.005.

Sharma, P., P. A. Munro, T. T. Dessev, and P. G. Wiles. 2016b. Shear work induced changes in the viscoelastic properties of model Mozzarella cheese. Int. Dairy J. 56:108-118. https://doi.org/10.1016/ j.idairyj.2016.01.010.

Sharma, P., P. A. Munro, T. T. Dessev, P. G. Wiles, and R. J. Buwalda. 2016a. Effect of shear work input on steady shear rheology and melt functionality of model Mozzarella cheeses. Food Hydrocoll. 54:266-277. https://doi.org/10.1016/j.foodhyd.2015.10.009.

Sharma, P. P. A. Munro, G. Gillies, T. T. Dessev, and P. G. Wiles 2017. Changes in creep behavior and microstructure of model Mozzarella cheese during working. Lebenson. Wiss. Technol. 83:184192. https://doi.org/10.1016/j.lwt.2017.05.003.

Taneya, S., T. Izutsu, T. Kimura, and T. Shioya. 1992. Structure and rheology of string cheese. Food Struct. 11:61-71.

van Vliet, T. 2008. Strain hardening as an indicator of bread-making performance: A review with discussion. J. Cereal Sci. 48:1-9. https://doi.org/10.1016/j.jcs.2007.08.010.

van Vliet, T. A. M. Janssen, A. H. Bloksma, and P. Walstra. 1992. Strain hardening of dough as a requirement for gas retention. J. Texture Stud. 23:439-460. https://doi.org/10.1111/j.1745-4603 .1992.tb00033.x.

Yang, X., N. R. Rogers, T. K. Berry, and E. A. Foegeding. 2011. Modeling the rheological properties of cheddar cheese with different fat contents at various temperatures. J. Texture Stud. 42:331-348. https://doi.org/10.1111/j.1745-4603.2011.00283.x.

Zhang, J., C. R. Daubert, and E. A. Foegeding. 2007. A proposed strain-hardening mechanism for alginate gels. J. Food Eng. 80:157-165. https://doi.org/10.1016/j.jfoodeng.2006.04.057.

Zheng, H., M. P. Morgenstern, O. H. Campanella, and N. G. Larsen. 2000. Rheological properties of dough during mechanical dough development. J. Cereal Sci. 32:293-306. https://doi.org/10.1006/ jcrs.2000.0339.

Zhou, N., and S. J. Mulvaney. 1998. The effect of milk fat, the ratio of casein to water, and temperature on the viscoelastic properties of rennet casein gels. J. Dairy Sci. 81:2561-2571. https://doi.org/10 $.3168 /$ jds.s0022-0302(98)75813-8. 